\title{
Discussions on Applications of CAI Bilingual Teaching for Technical Courses
}

\author{
Fengqin WANG \\ Xi'an Shiyou University, Xi'an, Shaanxi, 710065, China
}

\begin{abstract}
It is believed that many problems of application of CAI method for teaching technical courses still need to be solved by many years teaching practice. With a systematic analysis of the current problems of CAI method including the causes happened and its deterring factors, the CAI procedures of its adjustment, the improvement of teaching methods of the plan and considerations have been present. These could be references for improving and developing greatly the quality of technical courses with the CAI teaching method.
\end{abstract}

KEYWORD: CAI, Teaching method, Technical courses teaching

As rapid development of application of computer technology in the field of education, computerassisted instruction (CAI) that takes computer multimedia and network technology as a platform support has been widely recognized and universally used. However, how to make it play a better role in bilingual education for college technical courses and make full use of this means to raise the quality of bilingual teaching is one problem worthy in-depth discussion[1][2]. Otherwise, bilingual teaching cannot make full use of its advantages, but teaching form will separate from teaching subject, and courseware fabrication will be out of step with teaching method and teaching mode. Utilizing CAI for bilingual teaching of teaching courses right to constantly change, improve and update teaching methods and means can enable a original single teaching mode of tradition to develop an CAI bilingual teaching methods with an integrated effect of graphics, texts and voices. Giving full play to advantages of CAI will benefit bilingual teaching.

\section{PROMOTION OF CAI ON BILINGUAL TEACHING EFFECTS}

\subsection{Traditional teaching method}

Traditional teaching method has been widely used and is a practical and convenient school one, namely a teaching process that teachers explain teaching content to students through writing on the blackboard. As changes of teaching conditions and continual practice of teaching reformation, this traditional teaching method will more and more unsuitable, especially for teaching technical courses using foreign languages, become a more prominent issue. For example, technical courses need explain a lot of legends. If a teacher must map each legend on the blackboard, not only it is difficult to ensure effect and accuracy of drawn graphics, but also the arrangement of a entire class is unsatisfied; another problem is that foreign language teaching needs a lot of writing on the blackboard that occupies a lot of time. In addition, students do not understand uncommon technical vocabulary, which increases time of taking notes. After all, teachers write the foreign language, so the expression, the rate of correct spelling and writing speed are less convenient and fluent than using their own native language.

\subsection{CAI teaching method}

Sometimes special technical vocabularies must be written on the blackboard to solve the problem of inadequate hearing for students. Then naturally electric audio-visual instruction can be thought of to address this problem. At the beginning of application of CAI, many projection films and some color slides are produced in advance, meanwhile a small number of videos are taken as a teaching tool. The former includes a lot of texts, graphics and etc.. In other words, main blackboard writing content including the contents of chapters and summary of each stage has been finished, and both graphics context are luxuriant. With the accumulation of experience of bilingual teaching and continual improvement of hardware equipment of teaching, original so-called 
electronic teaching is advanced to CAI mode on the basis of computer[3][4]. On the basis of original materials, through accumulating teaching experience continually, and giving full play to the advantages of computer-aided teaching, upgrade these materials to CAI mode that takes the computer as main tool after regeneration and enrichment. Taking advantages of various audio visual classroom equipment to give rein to unique advantages of CAI for the course, organic integration of foreign language teaching, graphics, voice and a variety of interactive solves some difficulties of teachers on writing in a foreign language, so content is expressed more easily and clearly. Meanwhile, students are also more receptive, efficiency of lectures is improved, previous teaching method of "a blackboard, a chalk stresses to the end" is completely changed, so the course gains a better teaching results.

\section{REASONABLE COURSEWARE DESIGN OF CAI BILINGUAL TEACHING}

\subsection{The use of CAI in Technical courses}

Implementation of bilingual teaching for technical course first encounters a problem of language exchange. If teachers are mostly unable to apply English to express technical courses or students are unable to understand explanations, this course cannot proceed normally, and the students cannot learn professional knowledge at all. Therefore, the most basic requirement of bilingual teaching is to let the teachers express content successfully and make students understand well. While it should be made clear that this is a professional course rather than a language course. That is to say, not only achieve teaching purposes and requirements of this course, but also enable students to learn expertise that should be mastered.

\subsection{The reasonable CAI teaching Methods}

At the same time, take into account of actual situation of students, professional object, the nature of a course and expertise and the English level that students have mastered. Therefore, this factor must be considered fully in selection of teaching content and degree of difficulty, and the key factor should be grasped well in the production of courseware. That is to say, level of foreign languages of students should be taken into account of. For example, students first encounter a difficulty is unable to understand. If it takes a lot of time to explain the meaning of certain vocabulary or certain professional formulation, it is inferior to translate directly in Chinese. Enabling students to understand content, the simplest method is to explain each sentence through translation. However, this method is time-consuming and results in dependence of students, which goes against enhancement of hearing level. In order to help students get over this roadblock as soon as possible, this problem must be solved in production of CAI firstly. First, common professional vocabularies can be edited together, and their means are explained exclusively, and students are required to write these glossaries right. These glossaries do not need to talk about it anymore in the future lecture, while some commonly used classroom language are listed for the future. Therefore, students access to bilingual teaching environment more easily, which helps them to understanding teaching content. Thus, these factors mentioned above must be taken into account at the aspect of content and form of the production of CAI. Basic theories and concepts of professional with words of popular understandability should be provided, and a lot of illustrations and descriptions should be matched. Try to make certain vitality in the form of graphic presentation, so the rigid language is activated to make stiff graphics vary hierarchically. The versatility of software should be taken full advantage of, such as changing and highlighting sizes and depths of characters, changing light and shade of graphics, density of lines and using color changes to make description become more vivid, and various graphic solutions become more clear and acceptable. In the process of applying courseware, frequency of replacement pages should be paid attention to, sufficient time should be given to teachers to explain showed content and to students to think and understand the content.

\subsection{Let students know CAI}

On the grounds that bilingual teaching process is vivid and of strong fun, enthusiasm of students learning production of CAI courseware is enhanced. Bilingual teaching, which not only makes students master knowledge of production of CAI courseware, but also enhances the students' level of foreign languages and computer application, is warmly welcomed by students. In short, discussion on bilingual teaching method of CAI production, which is the need of times and conforms to characteristics and demands of this course, has a great significance in nurturing complex talent of the new century.

\section{CONSTANT INNOVATION OF CAI METHOD}

Application process of CAI teaching method is a continuous process of reformation and innovation; especially how to apply it better in the bilingual teaching is a long-term exploration and study process. The method need research problems that how teachers teach and how students study and etc., which requires to fully master two-way feedback information of teaching and learning between teachers and students to create a high efficient 
operation method of teaching interaction and scenes blend. Therefore, CAI bilingual teaching process can become a step-by-step process to overcome uniqueness of courseware demo process. Make demo screen maintain a certain continuity, arrange each teaching point in a pattern as possible, make each unit apply a unified manner and style of presentation, and then link them together organically. Namely, knowledge links should be included instead of a simple sequence between pictures. Single branch structure can be used, to handle complex of multi-branch structure, because generation type can form tree knowledge architecture according to content, learning path. $R \& D$ of generation structure is based on the systematic knowledge. At the same time, we cannot neglect the acceptance and existing level of students to pursue systematization unilaterally. If the structure is too complex, it will result in disorder of students' thinking, and tired learning behavior will be presented after a certain period. Thus, it not only cannot fully play to advantages of CAI teaching, but also enables students to generate tired emotion, which will curb the mastery of knowledge and the development of thinking ability. Therefore, at the time of production and application of CAI courseware, evolutionarily showed by content should be considered and objective laws of the teaching must be followed. In the process of teaching, teachers should pay constant attention to process development that students receive information to continuously adjust the teaching content and teaching progress. Various teaching hierarchy should be mastered, namely presenting content of proper hierarchy to students in proper circumstance to make students comprehend by analogy, and be suddenly enlightened to get twice the result with half the effort.

\section{EFFECTIVE APPLICATION OF CAI METHOD}

\subsection{To improve the CAI methods}

Teaching process is a two-way interactive process of teaching and learning, but CAI teaching should detach from those cramming methods to innovate various instructional forms of CAI in different teaching scenarios. It is necessary to explore how to combine topographical images that CAI owns with dynamic mechanism, activate study interests and enhance teaching effect through vivid image. Production and teaching process of CAI courseware are inseparable from scene explain, and teachers are always core designer and primary creators of CAI teaching. CAI is impossible to and cannot substitute main action of teachers entirely.

\subsection{To control the time and fervency of using CAI}

CAI is a process of combining the computer with various players and the large screen projector and demonstrating teaching content in the form of graphics, texts and voices on the large screen. Although it can present teaching content in a short period clearly, accurately and vividly, and raise teaching efficiency, it easily results in reducing teaching effect, because students cannot accept too much information in a short time. If they have maintained a highly centralized state at all time to make the brain always maintain "operation" of such high speed, it will easily result in fatigue of the students' thinking, and teaching has a counterproductive effect.

\subsection{To improve the study methods}

Students acquire new knowledge through teaching of teachers, and the whole teaching process should focus on the core to carry out a variety of teaching activities However, sometimes CAI brings confliction of teaching content and teaching forms, and makes teachers pay much attention to teaching mode or teaching form ${ }^{[5]}$. As a result students' attention is affected, and students' degrees of attention to effective teaching content are lowered, or interference of ineffective content with thinking understand of student is bound to affect the normal teaching and causes failure of achievement of our teaching objectives. Therefore, we must unify the forms and content, enable them to promote each other to bring out the best in each other and allow common development.

\section{CONCLUSION}

Implementation of bilingual teaching which makes use of CAI is a process of education reformation. Different approaches should be adopted for it according to different teaching content, teaching facilities, learning objects and teachers. Traditional teaching methods and CAI teaching methods should be combined organically to implement switch and complement mutually in time. Especially, particularity of bilingual teaching should be paid attention to. Make use of the advantages of CAI to make up for the shortcomings of traditional bilingual teaching, and give full play to special advantages of CAI on the basis of constantly reviewing and perfecting CAI bilingual teaching methods.

\section{REFERENCES}

[1] Yonghong Nie and Guo Deng. "Study of teach problem in CAI courseware." Journal of Guangxi University (Natural Science Edition), Vo 1. 27, Sup. June, pp121-125, 2002. 
[2] Haojie Yu and Ling Lu. "Several Questions about CAI Courseware Design and Development." Journal of Zhengzhou Institute of Aeronautical Industry Management, Vol 1. Jan. pp124-125, 2004.

[3] Shaoan Zhou and Yingru Su, "The Designing Strategies and Using Experiences for CAI Software." Journal of North China Institute of Astronautic Engineer, Vol. 10. 3, Sep. pp22-24, 2000.
[4] Jianhua Xing. "On the traditional teaching concepts and the combination of CAI." China Computer \& Communication, Vol. 1, Jan. pp.192-193, 2010.

[5] Ran Li. "The Design and Development of CAI Courseware." Journal of Dalian Nationalities University, Vol.5 No.1, Jan. pp. 26-27, 2003. 